\title{
Impact of Irrigation over the California Central Valley on Regional Climate $\mathscr{O}$
}

\author{
Zhao Yang, ${ }^{\mathrm{a}}$ Francina Dominguez, ${ }^{\mathrm{b}}$ Xubin Zeng, ${ }^{\mathrm{a}}$ Huancui Hu, ${ }^{\mathrm{b}}$ \\ HOSHIN GUPTA, ${ }^{\mathrm{a}}$ AND BEN YANG ${ }^{\mathrm{c}}$ \\ ${ }^{a}$ Department of Hydrology and Atmospheric Sciences, The University of Arizona, Tucson, Arizona \\ ${ }^{\mathrm{b}}$ Department of Atmospheric Sciences, University of Illinois at Urbana-Champaign, Urbana, Illinois \\ ${ }^{\mathrm{c}}$ School of Atmospheric Sciences, Nanjing University, Nanjing, China
}

(Manuscript received 6 July 2016, in final form 7 February 2017)

\begin{abstract}
Irrigation, while being an important anthropogenic factor affecting the local to regional water cycle, is not typically represented in regional climate models. An irrigation scheme is incorporated into the Noah land surface scheme of the Weather Research and Forecasting (WRF) Model that has a calibrated convective parameterization and a tracer package is used to tag and track water vapor. To assess the impact of irrigation over the California Central Valley (CCV) on the regional climate of the U.S. Southwest, simulations are run (for three dry and three wet years) both with and without the irrigation scheme. Incorporation of the irrigation scheme resulted in simulated surface air temperature and humidity that were closer to observations, decreased depth of the planetary boundary layer over the CCV, and increased convective available potential energy. The result was an overall increase in precipitation over the Sierra Nevada range and the Colorado River basin during the summer. Water vapor rising from the irrigated region mainly moved northeastward and contributed to precipitation in Nevada and Idaho. Specifically, the results indicate increased precipitation on the windward side of the Sierra Nevada and over the Colorado River basin. The former is possibly linked to a sea-breeze-type circulation near the $\mathrm{CCV}$, while the latter is likely associated with a wave pattern related to latent heat release over the moisture transport belt.
\end{abstract}

\section{Introduction}

\section{a. Background}

Humans are modifying climate from the regional to the global scale by changing the composition of the atmosphere and by land-use/land-cover changes (LULCC). Here, we focus on the effects of LULCC on climate, with specific attention to the impacts of agricultural irrigation. Water consumption by irrigation is known to account for about $2 \%$ of annual precipitation over land (Sacks et al. 2008), which, although relatively small when averaged over land, is large when considering only irrigated areas. Importantly, while irrigated cropland accounts for only $18 \%$ of the world's cropland or $2 \%$ of the total land (Siebert et al. 2005), about $40 \%$ of the world's food is produced in such areas and about $70 \%$ of global

Supplemental information related to this paper is available at the Journals Online website: http://dx.doi.org/10.1175/JHM-D-16-0158.s1.

Corresponding author e-mail: Francina Dominguez, francina@ illinois.edu freshwater withdrawals and $90 \%$ of consumptive water uses are used for irrigation (Siebert et al. 2013).

Irrigation can modify climate mainly by changing the partitioning of available energy, increasing the latent heat flux, and decreasing sensible heat flux when compared to nonirrigated regions. This repartitioning of available energy is more pronounced during the daytime, and the corresponding cooling of daytime near-surface temperatures (associated with reduced sensible heat flux) has been reported in several studies, using both observations and modeling (Bonfils and Lobell 2007; Han and Yang 2013; Qian et al. 2013; Marcella and Eltahir 2014).

Modeling studies have reported different magnitudes of irrigation cooling effects, depending on the irrigation schemes prescribed in their models (Qian et al. 2013; Ozdogan et al. 2010; Sacks et al. 2008; Sorooshian et al. 2011; Lo and Famiglietti 2013; Adegoke et al. 2003; de Rosnay et al. 2003; Haddeland et al. 2006; Kanamaru and Kanamitsu 2008; B. Yang et al. 2016). Most of these studies were performed at the regional scale. For example, Ozdogan et al. (2010) used the offline uncoupled Noah land surface model (LSM) to simulate the irrigation impact over the continental United States and 
showed that the energy fluxes and water budget over the irrigated area were significantly improved. At specific locations, inclusion of irrigation also greatly improved the simulated diurnal energy cycles when compared to AmeriFlux observations. Qian et al. (2013) used the regional Weather Research and Forecasting (WRF) Model to investigate impacts of irrigation over the southern Great Plains (SGP) region. They incorporated an irrigation scheme into the Noah LSM following Ozdogan et al. (2010) and found that sensible heat flux decreases (latent heat flux increases) leading to surface cooling of $0.3^{\circ}-0.5^{\circ} \mathrm{C}$ and increased surface air specific humidity of $0.3-0.6 \mathrm{~g} \mathrm{~kg}^{-1}$. In a relatively new approach, Marcella and Eltahir (2014) coupled the Integrated Biosphere Simulator (IBIS) dynamic vegetation model with a regional climate model and added a new irrigated cropland biome in which the only plant functional type (PFT) allowed to grow is crop. They found temperature decreases to be as large as $5^{\circ} \mathrm{C}$ in the irrigated area and an accompanying downstream cooling. Using the variableresolution Community Earth System Model (VRCESM), Huang and Ullrich (2016) found that irrigation over the California Central Valley (CCV) cools the daily maximum near-surface temperature by $1.1^{\circ} \mathrm{C}$. At the global scale, Sacks et al. (2008) investigated irrigation impacts using the Community Atmosphere Model (CAM) coupled with the Community Land Model. They found that irrigation cools the northern midlatitudes by about $0.5^{\circ} \mathrm{C}$ over the year but warms northern Canada by increasing the annual temperature by $1^{\circ} \mathrm{C}$. The cooling impact is dominated by indirect effects such as increased cloud cover, rather than direct evaporative cooling.

While a consensus emerges from these different studies with regards to daytime surface cooling, the effects of irrigation on nighttime temperatures is not as clear (Kanamaru and Kanamitsu 2008; Bonfils and Lobell 2007; Han and Yang 2013). Similarly, studies have reported different findings regarding irrigation effects on precipitation. Marcella and Eltahir (2014) reported decreased precipitation over the irrigated area due to the cooling effect and collapse of the boundary layer (i.e., the lower atmosphere is too cool for the PBL to grow enough to trigger convection). In contrast, other studies have reported precipitation enhancement due to irrigation (Lo and Famiglietti 2013; DeAngelis et al. 2010). For instance, Lo and Famiglietti (2013) used the CAM coupled with the Community Land Model to show that irrigation in the $\mathrm{CCV}$ can cause increased downwind summer precipitation of approximately $15 \%$ in the Colorado River basin (CRB), leading to $\sim 30 \%$ increased streamflow in the Colorado River. DeAngelis et al. (2010) found that the increased precipitation over and downwind of the Ogallala aquifer is consistent with the history of Ogallala irrigation, and they used a vapor tracking approach to demonstrate that evapotranspiration (ET) over Ogallala aquifer contributes to downwind precipitation. However, Qian et al. (2013) did not find a consistent precipitation signal over the southern Great Plains.

The focus of our work is similar to that of Lo and Famiglietti (2013) and Sorooshian et al. (2011) in that we study the impacts of CCV irrigation on regional hydroclimate. However, there are several important differences, beginning with the different irrigation schemes. In Sorooshian et al. (2011), irrigation starts when solar radiation is less than $50 \mathrm{~W} \mathrm{~m}^{-2}$, whereas in Lo and Famiglietti (2013), irrigation is prescribed as water added to irrigated area by fixed amount of $\sim 350 \mathrm{~mm} \mathrm{yr}^{-1}$ with $40 \%$ coming from groundwater and $60 \%$ from surface water. Next, in addition to analyzing surface variables as in Sorooshian et al. (2011), we also assess the impacts of irrigation on regional circulation and precipitation. Note that we are using a regional WRF Model for a total of 6 years of simulations whereas Lo and Famiglietti (2013) use the CAM, which is a global climate model with $\sim 140-\mathrm{km}$ grid spacing and simulations for a total of 90 years. Finally, the use of a water vapor tracer analysis tool to explicitly quantify both the direct and indirect impacts of irrigation on regional precipitation within WRF is an important part of our analysis.

\section{b. Objectives and scope}

As suggested by Sorooshian et al. (2011), a realistic irrigation scheme can be expected to improve the ability of a model to simulate the state variables associated with the impacts of irrigation on regional climate. Therefore, the first objective of this work is to investigate whether or not model performance can be improved by inclusion of a realistic irrigation scheme. We do this by implementing an explicit representation of irrigation into the WRF Model and by ensuring that an appropriate amount of water is used for irrigation.

Our second objective is to investigate the impact of $\mathrm{CCV}$ irrigation on local and regional climate, and our third objective is to distinguish between the direct and indirect impacts of such irrigation on local and regional climate. To do this, we use a water vapor transport scheme in the WRF Model to track the evapotranspirated water that arises from the irrigated source region (Miguez-Macho et al. 2013; Dominguez et al. 2016); the scheme tags the water vapor produced in the $\mathrm{CCV}$ region and tracks its movements in space and time. Depending on the physical processes experienced during the integration time period, water from the source region can be in the form of water vapor, cloud water, ice remaining in the atmosphere, precipitation, graupel, or snow falling on the ground. The use of a tracer scheme enables us to 


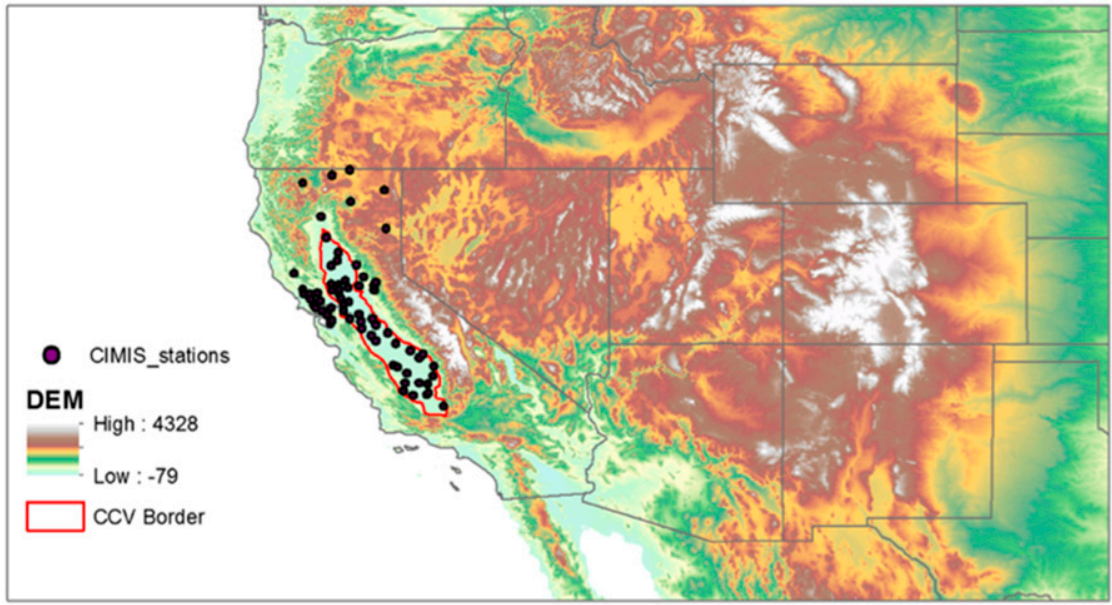

FIG. 1. Model domain, CIMIS stations, and areas equipped with irrigation.

differentiate between the direct and indirect impacts of a source region on local and regional climate. For example, if irrigation has induced precipitation enhancement in a certain location and is mainly due to moisture transport from the source region (e.g., the CCV), then this region is under the direct impact of irrigation over the source region. On the other hand, if irrigation has led to precipitation increase over a certain location without direct moisture contribution from the source region (e.g., by changing the atmospheric thermodynamics), then this location is under the indirect impact of irrigation in the source region.

This paper is organized as follows: the domain setup and experimental design, observational datasets, details of regional climate model [including the irrigation scheme and the modified Kain-Fritsch (KF) scheme], and water vapor transport scheme are described in section 2. Section 3 presents the model evaluation against the observations and details of the irrigation impact on climate variables. Conclusions and a discussion are provided in section 4 .

\section{Experiment design, data, and schemes}

\section{a. Experimental design and model setup}

In this work we apply the Advanced Research version of WRF (version 3.4.1; Skamarock et al. 2008) to a research domain that covers the southwestern United States, with irrigation applied only over the CCV (Fig. 1). The domain is located within $29.5^{\circ}-49.5^{\circ} \mathrm{N}$ and $131^{\circ}-99^{\circ} \mathrm{W}$ over the eastern Pacific and western United States, with a horizontal grid spacing of $20 \mathrm{~km}$ and 27 sigma levels from the surface to $100 \mathrm{hPa}$. WRF Model outputs are generated and saved at 3-hourly time intervals.

The physical parameterizations used in these WRF simulations are the Noah LSM (Chen and Dudhia 2001), the WRF single-moment 6-class microphysics scheme (WSM6; Hong and Lim 2006), the RRTM for longwave and shortwave (Mlawer et al. 1997), the Yonsei University (YSU) boundary layer parameterization (Hong and Pan 1996), and the KF convection scheme (Kain and Fritsch 1990). These parameterizations are chosen primarily because of the use of the water vapor tracers (see below). The WRF Model simulations include 1) the control simulation (CNTL) with the default Noah LSM without considering the irrigation and 2) the irrigation simulation (IRR) with an explicit representation of irrigation over the $\mathrm{CCV}$. Numerical water vapor tracers are used in all simulations. For each model setup, three dry years (i.e., 2002, 2007, and 2013) and three wet years (i.e., 2005, 2006, and 2010) are selected based on antecedent precipitation from January to May in California, in order to account for different initial soil moisture conditions. Since there is little precipitation (almost none) during June-August (JJA) over the $\mathrm{CCV}$, it is difficult to determine relative wet and dry years with it. On the other hand, accumulated precipitation from January to May determines the soil moisture condition at the beginning of June when irrigation demands start to grow, and our irrigation triggering algorithm is highly dependent on the soil moisture conditions. Thus, we define the relative wet and dry years based on the accumulated precipitation from January to May. The dry and wet years include both types of extreme precipitation conditions and thus should cover a representative spectrum of conditions that the model may encounter.

For each year, the model is initiated at three different dates from 1) 1 April, 2) 10 April, and 3) 15 April to 31 October, and we focus on the peak of the irrigation season (JJA) during which irrigation exerts the most significant impact. While previous studies have suggested that a 1-month spinup time is sufficient for such 
simulations (Liang et al. 2004; Li et al. 2007), for each ensemble member in this study we have used at least a 45-day spinup period. The North American Regional Reanalysis (NARR) data are used as lateral boundary forcing (Mesinger et al. 2006). Note that near-surface temperature in NARR is not assimilated and shows strong warm bias in NARR when compared to observation-based gridded dataset (Z. Yang et al. 2016; Huang et al. 2016; Loikith et al. 2015); however, the warm bias is significantly reduced by the WRF Model as shown later.

Water vapor tracers embedded into the WRF Model, version 3.4.1, allow us to trace moisture that evaporates from any predefined source (Miguez-Macho et al. 2013; Dominguez et al. 2016). We use water vapor tracers in all of the simulations. It is important to point out that water vapor tracers are currently only available for the YSU boundary layer scheme, WSM6, Noah LSM, and KF convective parameterization (although tracers can also be used at the convective-resolving scale). The tracer scheme, as applied to the cloud microphysics, assumes the atmosphere is well mixed within each grid and vertical level within the clouds.

\section{b. Observational data}

The California Irrigation Management Information System (CIMIS) dataset is used in this study to evaluate model performance against an observational dataset. The CIMIS has a network of over 145 automated weather stations in California and was designed to assist irrigators in managing their water resources more efficiently. Each CIMIS station collects meteorological variables, including near-surface temperature, radiation, humidity, winds, surface pressure, and soil temperature on a minute-by-minute basis. Hourly data reflect the previous hour's $60 \mathrm{~min}$ of readings. The farmers will estimate the amount and timing of irrigation based on the reference evapotranspiration, crop coefficient, crop type, and season (Hanson et al. 1999). The CIMIS data are considered to be of high quality (Sorooshian et al. 2011). In addition to the CIMIS data, PRISM data at 4-km resolution are used to evaluate the spatial pattern and magnitude of temperature and precipitation (PRISM Climate Group, available online at http://prism.oregonstate.edu/).

\section{c. Irrigation scheme}

To simulate the effects of irrigation, an irrigation scheme has been coupled to the land surface model in WRF. This irrigation scheme has been implemented in several previous studies (Ozdogan et al. 2010; Qian et al. 2013). Note that Ozdogan et al. (2010) proposed three key questions that an irrigation scheme must resolve: 1) where to irrigate, 2) when to irrigate, and 3) how much to irrigate. Therefore, the mechanism used for irrigation can be described as follows.

\section{1) WHERE TO IRRIGATE}

The irrigation fraction map was obtained from the Food and Agriculture Organization of the United Nations (Siebert et al. 2013). The irrigation map layer was developed to compute the fraction of irrigation at 5-arc-min resolution based on subnational irrigation statistics with geospatial information regarding the location and extent of irrigation. We compared the spatial pattern of the irrigation map to the MODIS and USGS data within the WRF Model and found that the USGS dataset has a more consistent spatial pattern compared to the irrigation fraction map. Accordingly, the USGS land-use and land-cover data were applied in this study; the spatial pattern of areas equipped for irrigation in the CCV is shown in the enclosed red area in Fig. 1.

\section{2) WHEN TO IRRIGATE}

Irrigation is triggered only when irrigation fraction is greater than zero and the greenness fraction in the Noah land model is above a certain threshold given by

$$
\mathrm{GF}_{\text {threshold }}=\mathrm{GF}_{\text {min }}+0.40 \times\left(\mathrm{GF}_{\text {max }}-\mathrm{GF}_{\text {min }}\right),
$$

where $\mathrm{GF}_{\max }$ and $\mathrm{GF}_{\min }$ are the annual maximum and minimum greenness fraction at a grid cell, respectively, and $\mathrm{GF}_{\text {threshold }}$ is the threshold set to determine whether the grid cell is in the growing season.

When the threshold of greenness fraction is met, the irrigation scheme examines the antecedent soil moisture condition, and a quantity named soil moisture availability [MA; see Eq. (2) below] is defined to determine the rootzone soil moisture availability [as in Ozdogan et al. (2010) and Qian et al. (2013)]. MA is defined as the ratio of the difference between the current root-zone soil moisture (SW) and the wilting point $\left(\mathrm{SM}_{\mathrm{WP}}\right)$ and the difference between field capacity $\left(\mathrm{SM}_{\mathrm{FC}}\right)$ and $\mathrm{SM}_{\mathrm{WP}}$, where field capacity is the maximum amount of water that the unsaturated zone of soil can hold against the pull of gravity. At 0600 local time (LT), the model examines the soil moisture condition and triggers the irrigation scheme only when MA is below the specific threshold. Once triggered, irrigation water is added at a uniform rate during 06001000 LT, until soil moisture reaches the field capacity (defined as maximum amount of water that the unsaturated zone of a soil can hold against the pull of gravity), at which point irrigation is stopped:

$$
\mathrm{MA}=\frac{\mathrm{SW}-\mathrm{SW}_{\mathrm{WP}}}{\mathrm{SW}_{\mathrm{FC}}-\mathrm{SW}_{\mathrm{WP}}} .
$$

\section{3) HOW MUCH TO IRRIGATE}

Lo and Famiglietti (2013) suggested an annual mean irrigation amount of $\sim 350 \mathrm{~mm}$ in the CCV. Over the same 
TABLE 1. Modified KF scheme parameters.

\begin{tabular}{clcc}
\hline \hline Parameter & \multicolumn{1}{c}{ Description } & Default/modified & Range \\
\hline $\mathrm{Pd}$ & Coef related to downdraft mass flux rate & $0 / 0.852$ & From -1 to 1 \\
$\mathrm{Pe}$ & Coef related to entrainment mass flux rate & $0 /-0.316$ & From -1 to 1 \\
$\mathrm{Ph}$ & Starting height of downdraft above USL $(\mathrm{hPa})$ & $150 / 331$ & From 50 to 350 \\
$\mathrm{Pt}$ & Max turbulent kinetic energy in subcloud layer $\left(\mathrm{m}^{2} \mathrm{~s}^{-2}\right)$ & $5 / 4.62$ & From 3 to 12 \\
$\mathrm{Pc}$ & Avg consumption time of CAPE $(\mathrm{s})$ & $2700 / 3386$ & From 900 to 7200 \\
\hline
\end{tabular}

region, Sorooshian et al. (2011) applied irrigation from June to August with a monthly average irrigation amount of about $107.5 \mathrm{~mm}$ for the entire irrigation region. We use the estimate of Sorooshian et al. (2011) because it matches observations. In our scheme, the water amount required for irrigation is determined by the difference between the current soil moisture content and field capacity at the trigger time, that is, when MA is below the specified threshold. Qian et al. (2013) used 50\% as the threshold for MA; however, we found that this value leads to an overestimation of irrigation over the region compared to that of Sorooshian et al. (2011) and Hanson et al. (1999). Accordingly, we calibrated the irrigation scheme so that the average monthly irrigation amount remains close to the benchmarks and found irrigation amount to be very sensitive to the choice of the threshold for MA; the best value for the threshold as found to be $43 \%$, which leads to realistic average monthly irrigation amount of $106.5 \mathrm{~mm}$.

\section{d. Modified KF scheme}

Parameterizations are used in the climate models to represent the unresolved subgrid-scale physical processes and to estimate the exchanges of mass, energy, and momentum (Kain and Fritsch 1990; Bechtold et al. 2001; Yang et al. 2012). However, physical parameterizations may introduce uncertainties in that they generally use conceptual or empirical relationships to approximate the subgrid-scale processes (Yan et al. 2014). Additionally, because of the nonlinearity of interactions among physical processes, large uncertainties may exist when parameterizations are applied in models. Consequently, it is necessary to tune the parameters within the parameterization schemes to ensure the proper representation of the physical process on the grid scale. In this study, a finely tuned convective parameterization scheme (i.e., the Kain-Fritsch scheme) was utilized following Yang et al. (2012) and Yan et al. (2014).

The KF convective parameterization is a onedimensional mass flux cloud model (Kain and Fritsch 1993; Kain 2004; Kain and Fritsch 1990). The scheme starts by identifying potential source layers for convective clouds, that is, the updraft source layer (USL) of a depth of at least $60 \mathrm{hPa}$. Convection is only possible when the USL has positive buoyancy and ascends. Deep convection is activated when vertical velocity remains positive over a depth that exceeds a specified minimum cloud depth. Otherwise, the base layer of the USL moves up one model layer and the procedure is repeated until the search reaches the lowest $300 \mathrm{hPa}$ of the atmosphere and terminates. Then convective updrafts, including entrainment and detrainment processes, and downdrafts are represented using a steadystate entraining-detraining plume model. Air mass is exchanged between the updraft and the environment by entrainment and detrainment. The rate of the entrainment mass flux rate is inversely proportional to the cloud radius as given in Kain and Fritsch (1990). The detrainment occurs by assuming the fractional amount of environment mass in the transition zone exceeds a certain neutrally buoyant mixture threshold. The downdraft is fueled by evaporation of condensate that is generated within the updraft and moves downward in a Lagrangian sense. The downdraft is terminated if it becomes warmer than its environment or if it reaches the ground (Kain 2004).

Previous studies have shown significant improvement in model precipitation by calibrating the convection scheme (i.e., KF scheme) in the model (Yang et al. 2012; Yan et al. 2014). As shown in Yang et al. (2012), the default KF scheme overestimates the frequency of precipitation across all rain rates, especially for heavy rains, whereas the calibrated KF scheme produces a much more realistic rain rate both in terms of magnitude and spatial pattern when compared to observations. Using the same approach, Yan et al. (2014) found that the optimized KF scheme not only reduces the overestimation of the precipitation, but it improves the representation of latent heat flux and net shortwave radiation as well. Here we follow the approach presented in Yang et al. (2012) and calibrate the critical parameters of the scheme. Brief descriptions and default values of the parameters are listed in Table 1. More details of the impact of the parameters on model precipitation can be found in Yang et al. (2012).

\section{Results}

\section{a. Model evaluation}

To ensure that the WRF Model is correctly simulating precipitation, we examined the convective 

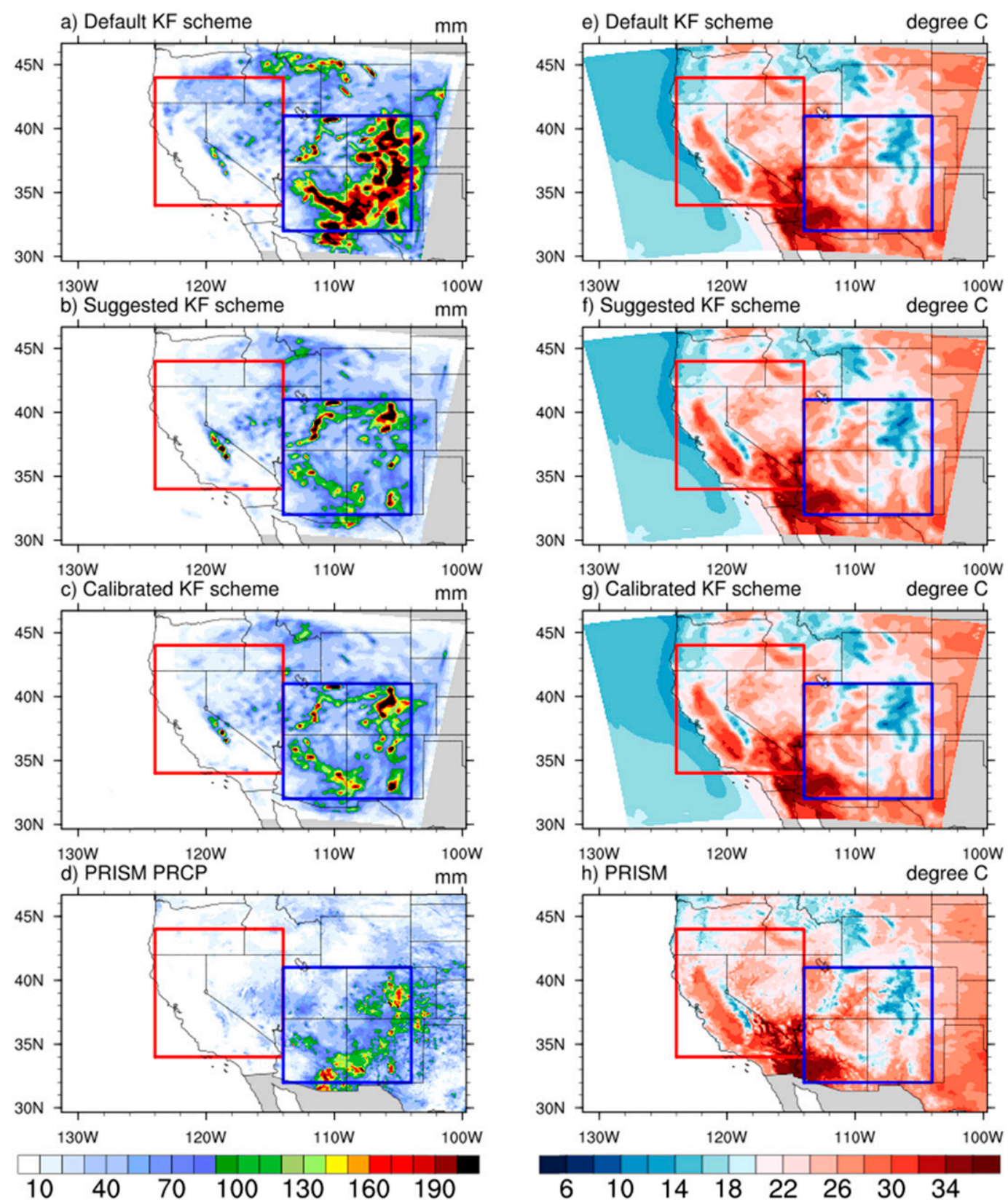

FIG. 2. Model-simulated July 2006 (left) total precipitation spatial pattern and (right) surface air temperature with (a),(e) default KF scheme; (b),(f) previously suggested KF scheme; and (c),(g) our calibrated KF scheme. (d),(h) Observational data are also shown. The red box contains California and its nearby region defined as CNR, and the blue box delineates the CRB.

parameterization scheme (i.e., KF scheme) in the model. Model simulations with 1) the default KF scheme, 2) the KF scheme with the parameter set as suggested in Yang et al. (2012), and 3) our own calibrated KF schemes were examined to ensure adequate model performance in simulating precipitation. Figure 2 shows the precipitation pattern for July 2006. The default KF scheme clearly overestimates precipitation-a common issue with the KF scheme (Yang et al. 2012). Using the KF parameters suggested by Yang et al. (2012), however, the model underestimates precipitation, with a precipitation band over the southeast of the domain missing, and overestimates precipitation over Utah. Thus, additional calibration of the KF scheme was required to alleviate these issues. The wet bias in domain-average monthly 
precipitation within the red box decreased from $+11.0 \mathrm{~mm}$ for the default $\mathrm{KF}$ scheme to $+7.8 \mathrm{~mm}$ for the suggested $\mathrm{KF}$ scheme and $+6.5 \mathrm{~mm}$ for the calibrated scheme. Similarly, for the blue box (roughly, the CRB), domainaverage monthly precipitation bias was $+69.9,+32.0$, and $+32.5 \mathrm{~mm}$ for the default, suggested, and calibrated $\mathrm{KF}$ schemes, respectively. The underestimation of precipitation band over New Mexico was also reduced when using our calibrated scheme. Overall, the overestimation of precipitation in the domain was significantly reduced by calibration of the KF scheme.

The spatial pattern of surface air temperature at $2 \mathrm{~m}$ for July 2006 is shown in Fig. 2 using the PRISM data. All of the model simulations produced a warm bias compared to PRISM, with $+0.20^{\circ},+0.06^{\circ}$, and $+0.10^{\circ} \mathrm{C}$ for the default, suggested, and calibrated KF schemes over the entire domain. Note that the warm bias in the NARR is $+0.8^{\circ} \mathrm{C}$ compared to PRISM and the WRF Model is able to significantly reduce the bias in the forcing NARR data. Overall, the warm bias in the domain was reduced with calibration. It is somewhat counterintuitive that the wetter default KF scheme produced warmer near-surface temperatures, particularly in the blue box (CRB) region where warm bias was $+2.2^{\circ},+1.5^{\circ}$, and $+1.5^{\circ} \mathrm{C}$ for the default, suggested, and calibrated $\mathrm{KF}$ schemes, respectively. Figure 2 shows that, compared with the default KF scheme, the calibrated scheme reduced the probability of convective rainfall and thus the wet bias. As a result, the vertical structure of clouds (Fig. S1 in the supplemental material) and the net radiation at the surface (Table S1 in the supplemental material) was changed, as discussed in the supplemental material.

\section{b. Irrigation impact}

To ensure the amount of irrigated water applied to the $\mathrm{CCV}$ is realistic when compared to the benchmark values, the threshold of moisture availability was calibrated, it being the most sensitive parameter in controlling irrigation water amount.

We focused on the results of JJA since irrigation peaks during this period. Figure 3 compares the simulated diurnal cycle of 2-m mean air temperature, relative humidity, and dewpoint temperature over CCV with the observational CIMIS data. The additional water introduced by the irrigation scheme reduces the warm bias by $\sim 0.7^{\circ} \mathrm{C}$ from $+2.62^{\circ} \mathrm{C}$ in the $\mathrm{CNTL}$ simulation to $+1.94^{\circ} \mathrm{C}$ in the IRR simulation. There is a clear difference between the IRR and CNTL simulations in the 2-m air temperature during the daytime (0700-1900 LT), and the difference gradually diminishes at night.

It is apparent that the CIMIS surface air temperature is lower than both IRR and CNTL simulations during the daytime. This can be explained by the fact that the
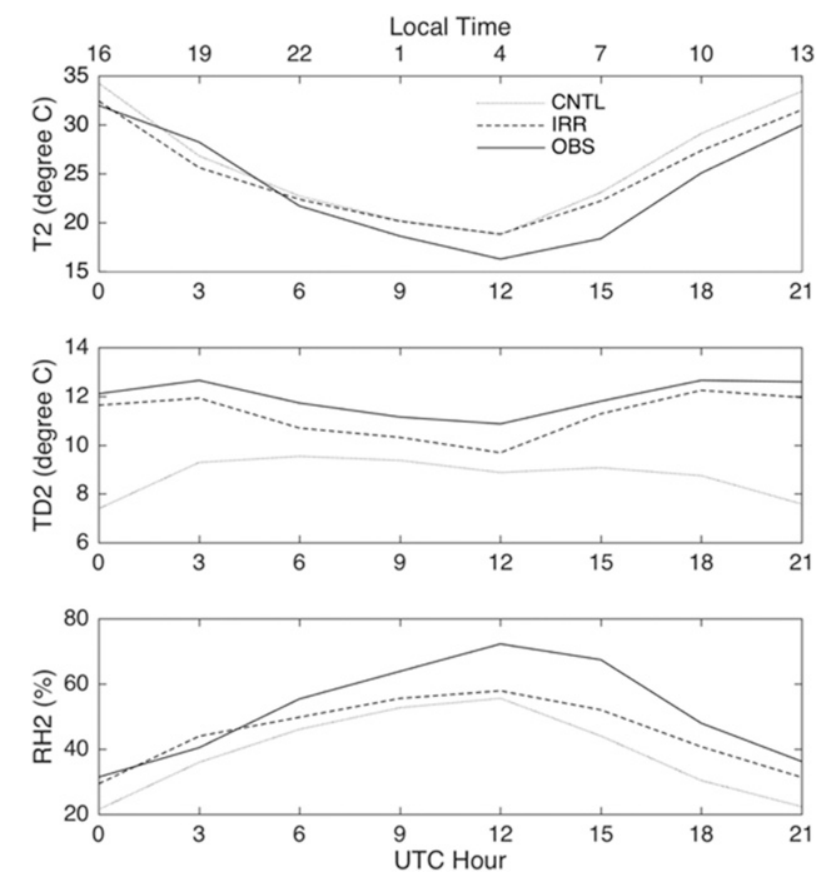

FIG. 3. Diurnal cycle of (top) $T_{2}$, (middle) $\mathrm{TD}_{2}$, and (bottom) $\mathrm{RH}_{2}$ from the CIMIS observations and the CNTL and IRR simulations.

CIMIS observations were measured under saturated conditions, while the model crops are not in saturated soil moisture conditions. Indeed, as shown in Sorooshian et al. (2011), temperature is much closer to the CIMIS observational data when a high value for the soil moisture allowable depletion parameter is applied. However, the warm bias in the WRF Model that was discussed earlier may also lead to the differences between CIMIS and simulations. It is not clear why CIMIS temperature is warmer than IRR simulation during 1700-2100 LT, though a similar result has been reported in Sorooshian et al. (2011). Dewpoint temperature shows very similar diurnal variation pattern to the CIMIS data with irrigation scheme, as the mean absolute bias reduces from $3.2^{\circ} \mathrm{C}$ in the $\mathrm{CNTL}$ simulation to $0.7^{\circ} \mathrm{C}$ in the IRR simulation. Similarly, relative humidity is also improved in the IRR simulation with mean absolute bias of $13.3 \%$ without irrigation to $7.7 \%$ with the irrigation scheme. During daytime from 0700 to 1900 LT, mean absolute bias is reduced by $1.6^{\circ} \mathrm{C}, 3.6^{\circ} \mathrm{C}$, and $8.8 \%$ for nearsurface temperature, dewpoint, and relative humidity in the IRR simulation, respectively. The effect of the irrigation scheme is less significant during the night (1900$0700 \mathrm{LT}$ ), with bias slightly reduced by $1.3^{\circ} \mathrm{C}$ and $2.4 \%$ for dewpoint temperature and relative humidity, respectively, and bias in near-surface temperature slightly increased by $0.2^{\circ} \mathrm{C}$. With the representation of irrigation, the diurnal variation of near-surface temperature, 
TABLE 2. Bias, RMSE, and correlation of simulated model results when compared to CIMIS observations for surface air temperature, dewpoint temperature, relative humidity, and first-layer soil temperature. Model results are extracted from irrigated grids that are closest to the CIMIS stations. Boldface numbers indicate that the absolute bias in the IRR simulation is less than that in the CNTL simulation, statistically significant at $p=0.05$ using the two-sample $t$ test.

\begin{tabular}{|c|c|c|c|c|c|c|c|c|}
\hline \multirow[b]{2}{*}{ Variables } & \multicolumn{2}{|c|}{$T_{2}$} & \multicolumn{2}{|c|}{$\mathrm{TD}_{2}$} & \multicolumn{2}{|c|}{$\mathrm{RH}_{2}$} & \multicolumn{2}{|c|}{ TSLB } \\
\hline & IRR & CNTL & IRR & CNTL & IRR & CNTL & IRR & CNTL \\
\hline \multicolumn{9}{|l|}{2002} \\
\hline Mean & 26.51 & 27.59 & 11.10 & 8.46 & 40.52 & 33.71 & 25.24 & 27.44 \\
\hline Bias & 2.58 & 3.66 & -1.30 & -3.95 & -9.07 & -15.88 & 1.56 & 3.76 \\
\hline RMSE & 2.69 & 3.78 & 1.94 & 4.33 & 11.00 & 17.38 & 2.05 & 3.96 \\
\hline Correlation & 0.98 & 0.91 & 0.13 & -0.16 & 0.93 & 0.29 & 0.97 & 0.81 \\
\hline \multicolumn{9}{|l|}{2007} \\
\hline Mean & 25.70 & 26.94 & 11.15 & 8.16 & 42.71 & 34.73 & 24.62 & 27.53 \\
\hline Bias & 1.56 & 2.80 & -0.52 & -3.51 & -4.15 & -12.13 & 0.72 & 3.63 \\
\hline RMSE & 1.84 & 3.02 & 1.72 & 3.96 & 7.79 & 14.15 & 1.81 & 4.11 \\
\hline Correlation & 0.98 & 0.82 & 0.52 & 0.16 & 0.95 & 0.50 & 0.96 & 0.61 \\
\hline \multicolumn{9}{|l|}{2013} \\
\hline Mean & 26.04 & 27.29 & 11.63 & 8.80 & 43.17 & 35.39 & 24.79 & 27.74 \\
\hline Bias & 1.61 & 2.87 & -0.64 & -3.46 & -5.25 & -13.02 & 1.09 & 4.04 \\
\hline RMSE & 1.86 & 2.94 & 1.46 & 3.57 & 8.21 & 14.27 & 1.97 & 4.26 \\
\hline Correlation & 0.98 & 0.80 & 0.26 & 0.35 & 0.94 & 0.56 & 0.97 & 0.52 \\
\hline \multicolumn{9}{|l|}{2005} \\
\hline Mean & 25.44 & 26.48 & 11.26 & 8.70 & 43.86 & 37.19 & 24.29 & 26.41 \\
\hline Bias & 1.00 & 2.05 & -0.99 & -3.55 & -3.88 & -10.55 & $\mathbf{0 . 3 9}$ & 2.50 \\
\hline RMSE & 1.31 & 2.30 & 2.06 & 4.18 & 8.59 & 13.76 & 1.40 & 3.15 \\
\hline Correlation & 0.99 & 0.91 & 0.47 & -0.06 & 0.97 & 0.30 & 0.97 & 0.66 \\
\hline \multicolumn{9}{|l|}{2006} \\
\hline Mean & 26.42 & 27.47 & 11.73 & 9.10 & 42.60 & 35.77 & 25.16 & 27.44 \\
\hline Bias & 1.63 & 2.68 & -1.22 & -3.84 & -6.63 & -13.45 & 0.91 & 3.19 \\
\hline RMSE & 1.81 & 2.84 & 2.12 & 4.38 & 10.16 & 15.98 & 1.82 & 3.84 \\
\hline Correlation & 0.99 & 0.90 & 0.63 & 0.12 & 0.97 & 0.38 & 0.97 & 0.50 \\
\hline \multicolumn{9}{|l|}{2010} \\
\hline Mean & 23.80 & 24.81 & 9.86 & 6.97 & 44.00 & 36.47 & 23.19 & 25.67 \\
\hline Bias & 0.26 & 1.27 & -1.56 & -4.45 & -3.96 & -11.49 & -0.53 & 1.95 \\
\hline RMSE & 0.89 & 1.59 & 2.33 & 4.85 & 8.07 & 13.94 & 2.15 & 3.01 \\
\hline Correlation & 0.98 & 0.87 & 0.50 & 0.24 & 0.96 & 0.55 & 0.96 & 0.39 \\
\hline
\end{tabular}

dewpoint, and relative humidity show greater improvements during the daytime than during the nighttime. This has to do with the timing of irrigation, which is from 0600 to 1000 LT. Irrigation-induced additional water evaporates mainly during the day and changes the energy partitioning. Because evapotranspiration is very limited at night, the IRR and CNTL simulations are similar during the nighttime.

Table 2 provides statistical results of averaged surface variables from observational CIMIS data and model results with, and without, the irrigation scheme. There are nine CIMIS stations that the model categorized as irrigation grids, of which one station was inactive in 2013. Overall it is very close to eight stations, as indicated in Sorooshian et al. (2011). Model results are biased in the control runs, but when irrigation is included into the model, results are improved in regards to near-surface 2-m air temperature $T_{2}$, dewpoint temperature $\left(\mathrm{TD}_{2}\right)$, relative humidity $\left(\mathrm{RH}_{2}\right)$, and first-layer soil temperature (TSLB) in both wet and dry years.
While improvement in the near-surface temperature due to the irrigation scheme seems to be minor, bias and RMSE decrease by $39 \%$ and $32 \%$, respectively. Improvement in moisture-related variables increases significantly, biases are reduced by $72 \%$ and $56 \%$, and RMSE is reduced by $50 \%$ and $38 \%$ in $\mathrm{TD}_{2}$ and $\mathrm{RH}_{2}$, respectively. Because of the inclusion of the irrigation scheme, bias and RMSE in TSLB are reduced by $64 \%$ and $42 \%$, respectively.

In summary, the comparison with the CIMIS data shows that the additional water added by the irrigation scheme results in cooler and wetter conditions over the $\mathrm{CCV}$. The detailed comparison of our model simulations with CIMIS data shows that surface variables, such as surface air temperature, dewpoint temperature, and relative humidity, as well as soil temperature, are improved by introduction of a realistic irrigation scheme.

Next, changes in other climatic variables caused by the irrigation scheme are examined to determine the impact of the irrigation scheme on local and regional climate. Results are averaged over all years and initial 

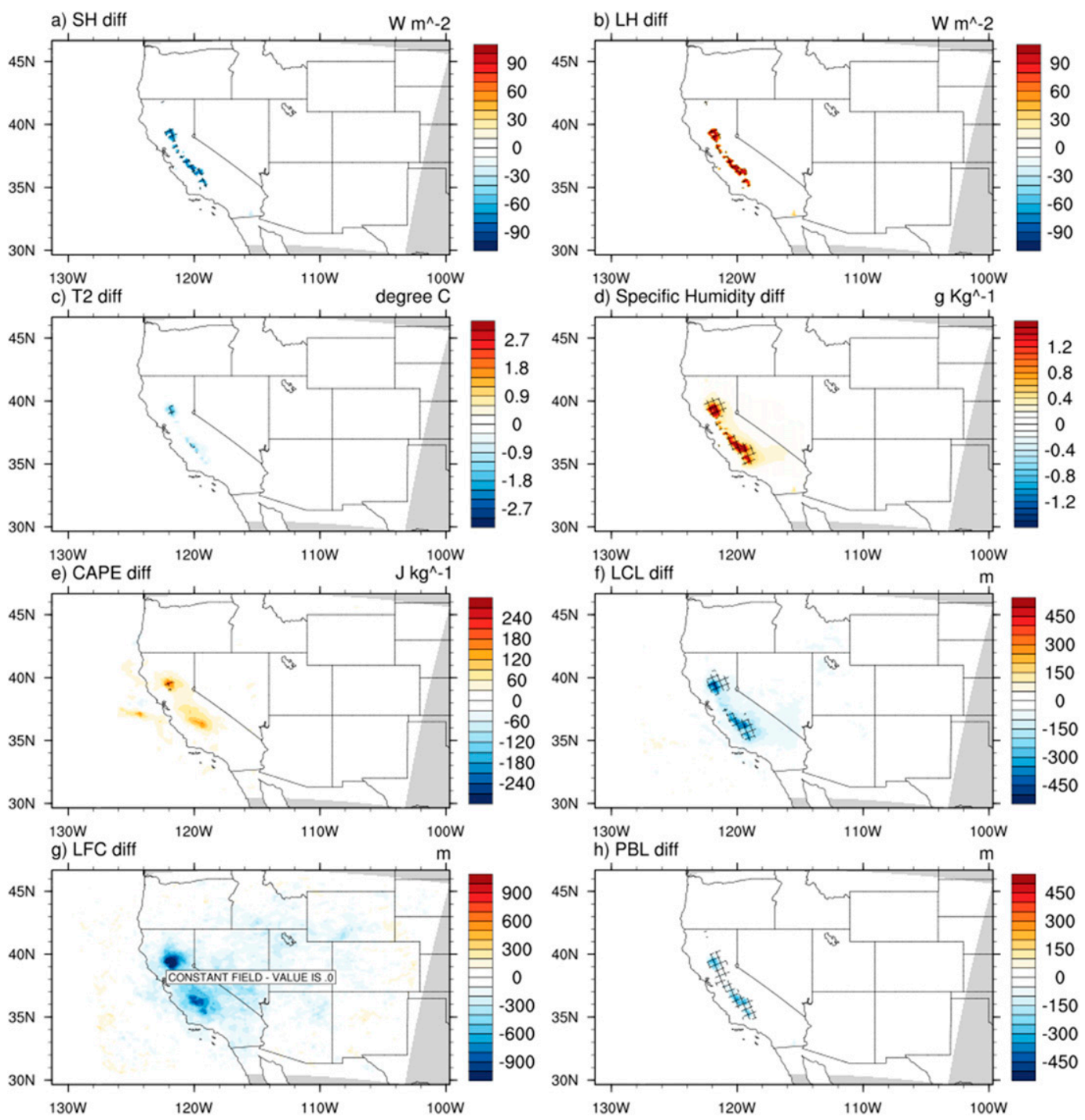

FIG. 4. Simulated differences between the IRR and CNTL simulations in (a) SH ( $\left.\mathrm{W} \mathrm{m}^{-2}\right)$, (b) $\mathrm{LH}\left(\mathrm{W} \mathrm{m}^{-2}\right)$, (c) $T_{2}\left({ }^{\circ} \mathrm{C}\right)$, (d) specific humidity $\left(\mathrm{g} \mathrm{kg}^{-1}\right)$, (e) CAPE $\left(\mathrm{J} \mathrm{kg}^{-1}\right)$, (f) LCL (m), (g) LFC (m), and (h) PBL height (m). Stippled areas indicate that differences between IRR and CNTL are statistically significant using the two-sample $t$ test at $P=0.05$.

condition ensemble members and are presented as the difference between the IRR and CNTL simulations.

Figures $4 \mathrm{a}-\mathrm{d}$ show the spatial pattern of difference in sensible heat flux (SH), latent heat flux ( $\mathrm{LH}), T_{2}$, and specific humidity at $2 \mathrm{~m} Q_{2}$ between the IRR and CNTL simulations. Irrigation increases ET over this region. The additional water changes the surface energy partitioning, leading to more $\mathrm{LH}$ and less SH. Averaging over the irrigated grids, LH is almost doubled and increases by $32.10 \mathrm{~W} \mathrm{~m}^{-2}$ while sensible heat flux decreases by $23.80 \mathrm{~W} \mathrm{~m}^{-2}(22.4 \%)$ over the same region. Meanwhile specific humidity increases by about $10 \%$ with $0.68 \mathrm{~g} \mathrm{~kg}^{-1}$ more water vapor over the $\mathrm{CCV}$, and a relatively smaller amount of increase is also shown downwind. Because of the decrease in $\mathrm{SH}, T_{2}$ is decreased by $0.39^{\circ} \mathrm{C}$. Changes in these surface variables have mainly a local effect and do not extend into other regions.

The planetary boundary layer (PBL) strongly affects the exchange of mass, momentum, and energy between the surface and the atmosphere. The PBL is directly influenced by Earth's surface, and its depth is a reflection of surface roughness, wind speed, and surface fluxes. Lifting condensation level (LCL) is the level at which an air parcel becomes saturated when lifted adiabatically from the surface. It is strongly related to the PBL structure and affected by the partitioning of 

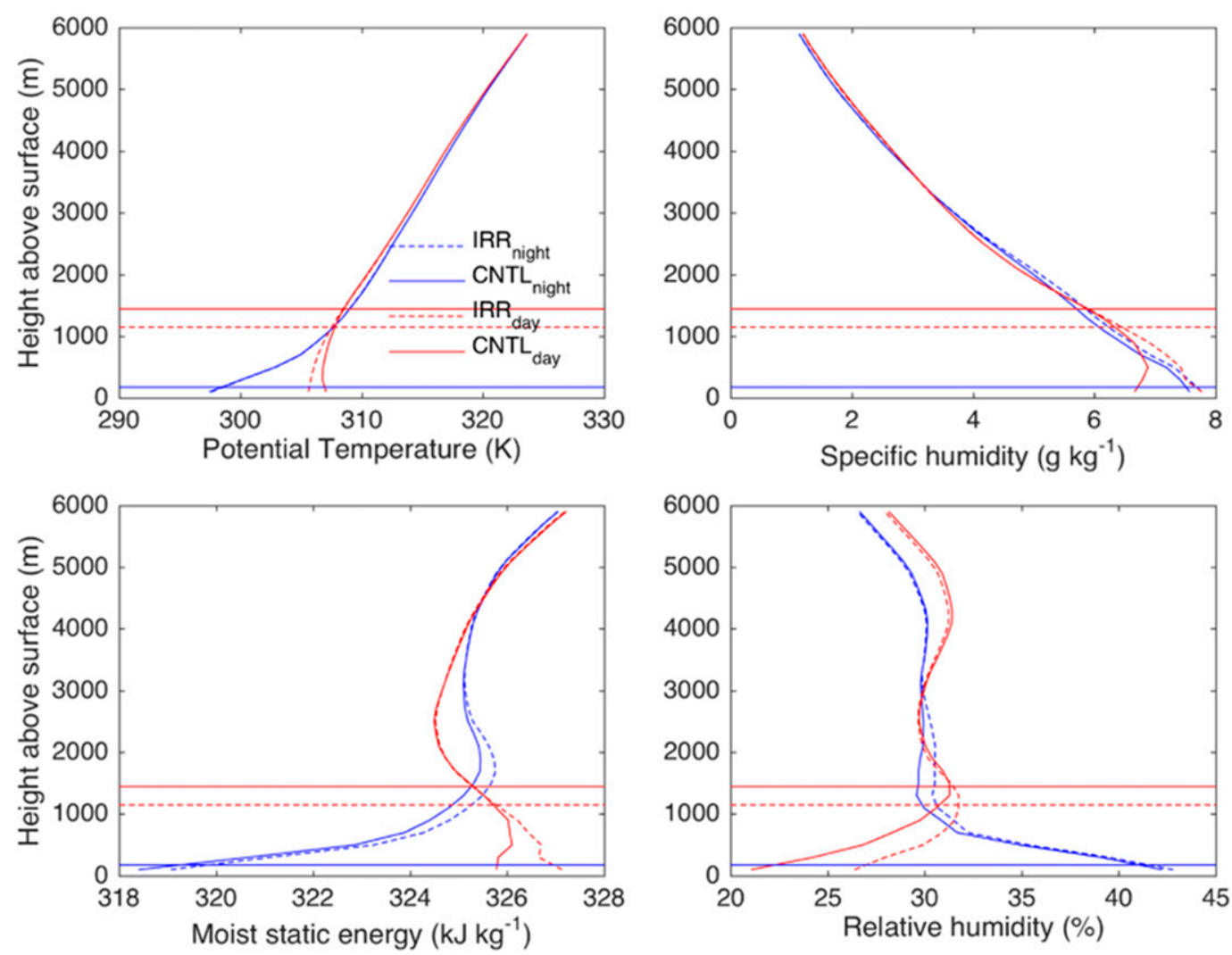

FIG. 5. Vertical profiles of potential temperature (K), specific humidity $\left(\mathrm{g} \mathrm{kg}^{-1}\right), \mathrm{MSE}\left(\mathrm{kJ} \mathrm{kg}^{-1}\right)$, and relative humidity (\%) in the daytime (red) at 1300 LT and nighttime (blue) at 0100 LT from IRR (dashed line) and CNTL (solid line) simulations. Horizontal lines represent the PBL height.

available energy at the surface. Generally, the height of LCL and the time of convection initiation are related to the boundary layer structure (Berg and Kassianov 2008). Moist convection is likely to initiate when the PBL depth crosses the LCL (the so-called LCL crossing; Ek and Mahrt 1994; Ek and Holtslag 2004; Juang et al. 2007). In our simulations, irrigation-induced decrease in PBL depth over the CCV is $103.16 \mathrm{~m}$ while decrease in LCL depth is $179.2 \mathrm{~m}$, indicating a higher probability of LCL crossing in the irrigation simulations (Fig. 4).

Meanwhile, the level of free convection (LFC) decreases by $526.78 \mathrm{~m}$ over the CCV and its downwind region, making it easier for convection to develop. Both higher probability of LCL crossing and decreasing in LFC increase the chances of precipitation. However, LCL crossing is a necessary but not sufficient condition for the initiation of deep convection (Yin et al. 2015; Juang et al. 2007). Convective available potential energy (CAPE) should also be considered at the time of LCL crossing in order for moist convection to occur. CAPE typically must exceed $400 \mathrm{~J} \mathrm{~kg}^{-1}$ to trigger convective rainfall in the midlatitude continental regions (Battan 1973; Findell and Eltahir 2003). Particularly, irrigation has induced an area-averaged increase in CAPE of about $58.89 \mathrm{~J} \mathrm{~kg}^{-1}$ ( $\sim 20 \%$, see Fig. 4). The increase in CAPE along with LCL crossing suggests that it is more likely to form precipitation in the IRR simulation over the CCV. However, as shown later, there is no significant change in precipitation over the CCV. Climatologically, precipitation over the $\mathrm{CCV}$ is at a minimum during the summer so local changes are negligible.

The amount of moisture within the PBL and surface heating are key regulators in cloud formation and involved in critical processes through which land and atmosphere interact (Qian et al. 2013). Changes induced by irrigation and associated changes in the land-atmosphere feedback can have an impact on the thermodynamic structure of the PBL. To investigate the irrigation impact on the vertical structure of several key thermodynamic variables, profiles of these variables over the CCV have been created at 1300 LT during the day and 0100 LT at night (Fig. 5).

During the daytime, nearly constant potential temperature and specific humidity should be expected within the PBL due to turbulent mixing. Such a pattern is clear for control simulations at 1300 LT in Fig. 5. As for the irrigation simulations, since the timing is only $3 \mathrm{~h}$ 


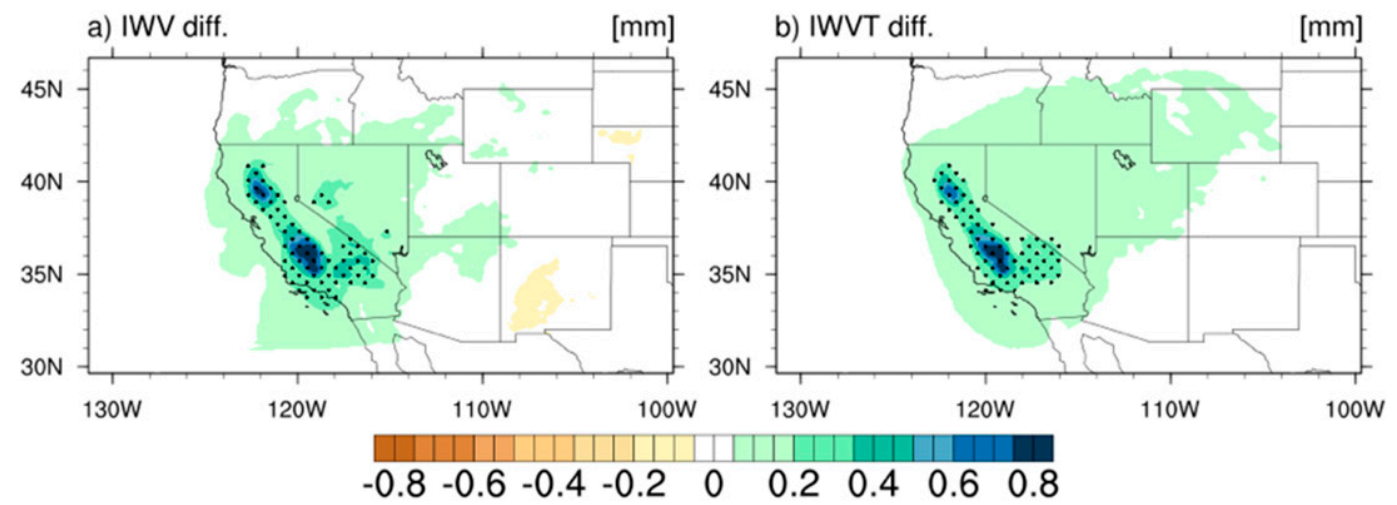

FIG. 6. (a) IWV and (b) IWVT differences between the IRR and CNTL simulations. Stippled areas indicate that differences between IRR and CNTL are statistically significant using the two-sample $t$ test at $P=0.05$.

after irrigation ended, vertical mixing is likely not able to bring surface moisture to the upper PBL in a short time. Moist static energy (MSE) is an important indicator for moist static instability, and a higher MSE is likely to increase convective instability and thereby increase the probability of precipitation (Eltahir 1998). Domain-averaged MSE in the PBL is clearly increased because of irrigation during the day. Relative humidity is also increased throughout the PBL.

Similar profiles for the nighttime at $0100 \mathrm{LT}$ are shown in Fig. 5. During the nighttime, the PBL is stable because of radiative cooling, as evident in the potential temperature profile. Potential temperature is almost the same for the IRR and CNTL simulations, because evapotranspiration is weak at night. The difference in specific humidity is much smaller than during the day and mainly exists in the lower levels. There is, however, a clear difference in MSE and relative humidity between the irrigation and control simulations, particularly in the midlevels between 1000 and $3000 \mathrm{~m}$, where the residual layer is present. The vertical profile of relative humidity difference between IRR and CNTL simulations from 1300 to 0100 LT is shown in Fig. S2 in the supplemental material. It shows that there exists a large relative humidity difference at lower levels at 1300 LT, and the additional moisture in the IRR simulation is gradually transported to higher levels with the growth of PBL at 1600 LT. After sunset, the PBL starts to shrink and the additional moisture remains in the residual layer and leads to the difference in the relative humidity vertical profile. The difference in MSE is directly related to the difference in the moisture in the midlevels.

\section{c. Water vapor transport: How irrigation in $C A$ affects precipitation downwind}

Figure 6 shows the difference in integrated water vapor (IWV) between the IRR and CNTL simulations.
Overall, IWV is clearly increased over the CCV and slightly increased over the downwind region, indicating that the irrigation scheme has significantly increased atmospheric moisture, as expected. We also plot the IWV that originates from the tracers of irrigated water (IWVT). As expected, the results show similar spatial patterns and magnitudes, indicating that changes in the IWV are mostly due to the additional water input by the irrigation scheme.

To understand the difference in spatial patterns shown in Fig. 6, we analyze the moisture transport. Figure 7 shows the water vapor mixing ratio difference along with average wind patterns at different model levels from 800 to $500 \mathrm{hPa}$. Moisture mainly exists from the surface to about $600 \mathrm{hPa}$. Moisture differences mainly occur in the lower atmosphere and diminish gradually with increasing height. Differences in water vapor between the IRR and CNTL simulations are almost negligible around the 600-hPa level.

The wind field is affected by the North Pacific high pressure to the west and the Bermuda high to the southeast of the domain. This is evident from the wind pattern in Fig. 7. Near the surface over the Pacific Ocean, wind is typically northerly in the northwest because of the Pacific high and becomes north-northwesterly in the southwest. Over land, wind directions are complicated by the terrain effect. Wind is typically affected by the Bermuda high and becomes south-southwesterly over California and Arizona, which brings the extra moisture northeastward from the CCV to its downwind region, for example, Nevada and Utah. Such a pattern is well reflected in the water vapor differences (shaded) in the lower levels, leading to a positive anomaly in water vapor in Nevada, Utah, and southern Idaho.

\section{d. Quantitative analysis of water vapor flux over the $C C V$}

To estimate water vapor transport over the $\mathrm{CCV}$, zonal and meridional fluxes are analyzed. A simplified 


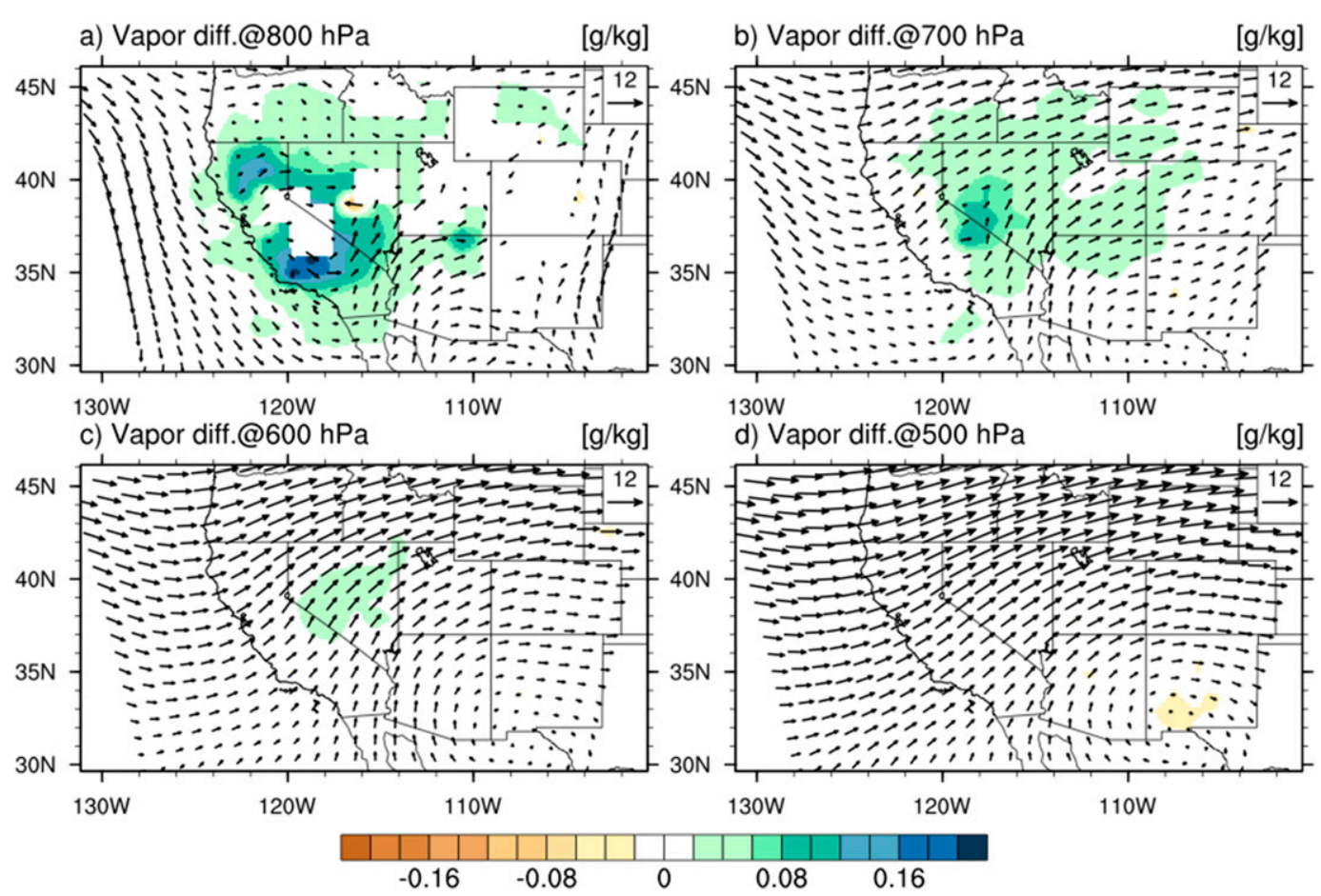

FIG. 7. Shaded regions indicate the water vapor mixing ratio $\left(\mathrm{g} \mathrm{kg}^{-1}\right)$ difference between the IRR and CNTL simulations at (a) 800 , (b) 700, (c) 600 , and (d) $500 \mathrm{hPa}$. Vectors indicate the winds at each level.

approximation of the CCV region is shown in Fig. 8. Zonal flux moves into the CCV through sides 1 and 2 (influx) and out through sides 4 and 5 (outflux). Similarly, meridional flux moves in through sides 2 and 3 (influx) and out through sides 5 and 6 (outflux).

By considering irrigation over the $\mathrm{CCV}$, the model has led to increased atmospheric moisture, as shown earlier. Zonal influx slightly decreases from $(7.93 \pm 1.45) \times 10^{13}$ to $(7.89 \pm 1.45) \times 10^{13} \mathrm{~kg} \mathrm{month}^{-1}$ while zonal outflux increases from $(5.50 \pm 1.12) \times 10^{13}$ to $(5.74 \pm 1.17) \times$ $10^{13} \mathrm{~kg} \mathrm{month}^{-1}$, leading to net zonal flux decreases from $(2.43 \pm 0.80) \times 10^{13}$ to $(2.15 \pm 0.82) \times 10^{13} \mathrm{~kg} \mathrm{month}^{-1}$. Here, numbers in the parentheses indicate the mean plus/minus two standard deviations. Meridional influx and outflux both decrease. Considering the increased water vapor over the $\mathrm{CCV}$, it implies that irrigation has induced a weaker northerly flow over the CCV. Overall, the meridional net flux does not change much, slightly decreasing from $(-2.57 \pm 0.82) \times 10^{13}$ to $(-2.50 \pm 0.86) \times 10^{13} \mathrm{~kg}$ month $^{-1}$. The net impact of irrigation on moisture flux mainly reflects in the zonal direction, leading to a weaker influx and stronger outflux, while the net impact in the meridional direction is almost negligible compared to changes in the zonal moisture flux.

A similar analysis is performed on tracer moisture (numbers shown in the parentheses in Fig. 8, bottom).
It shows that tracer moisture flux has been strengthened in all directions. Particularly in the meridional direction, stronger tracer flux to the north and south indicates that there is a low-level divergence over the $\mathrm{CCV}$, as shown later.

The convergence term is calculated from the moisture budget equation over the CCV [see details in Schmitz and Mullen (1996)] and the results above suggest that irrigation induces stronger divergence over the CCV during the JJA months, as shown in Fig. 9. As a result, divergence over the CCV generates outflows to the west and east, weakening the zonal moisture influx while strengthening the zonal outflux from the CCV. The moist eastward flow has a potential to rise orographically along the Sierra Nevada range and induce topographic precipitation as displayed in the precipitation difference pattern in Fig. 10. Under both dry and wet conditions, a consistent increase in precipitation is present on the windward side of the Sierra Nevada range (not shown). Over the CCV, the divergence and the stability variables in section $3 \mathrm{~b}$ act as opposing mechanisms for precipitation, leading to a negligible change in precipitation over the CCV.

\section{e. Precipitation and tracer precipitation}

Figure 10 displays the precipitation and tracer precipitation in CNTL simulation in all years and their 


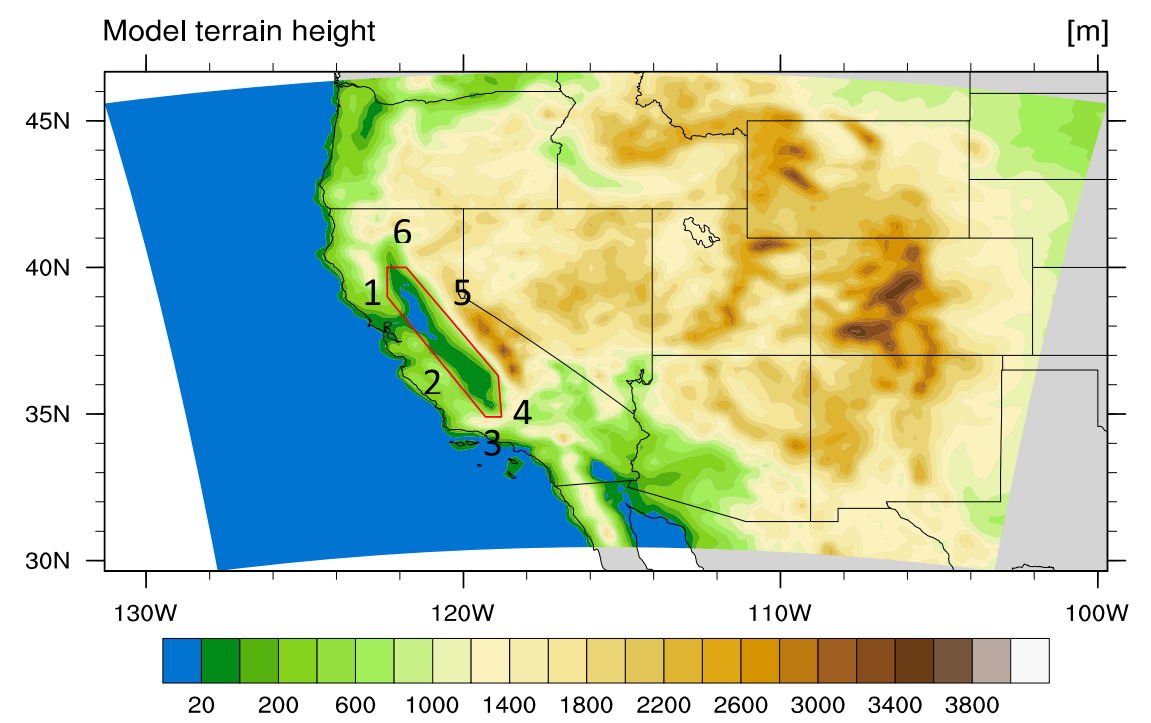

Vertically integrated moisture
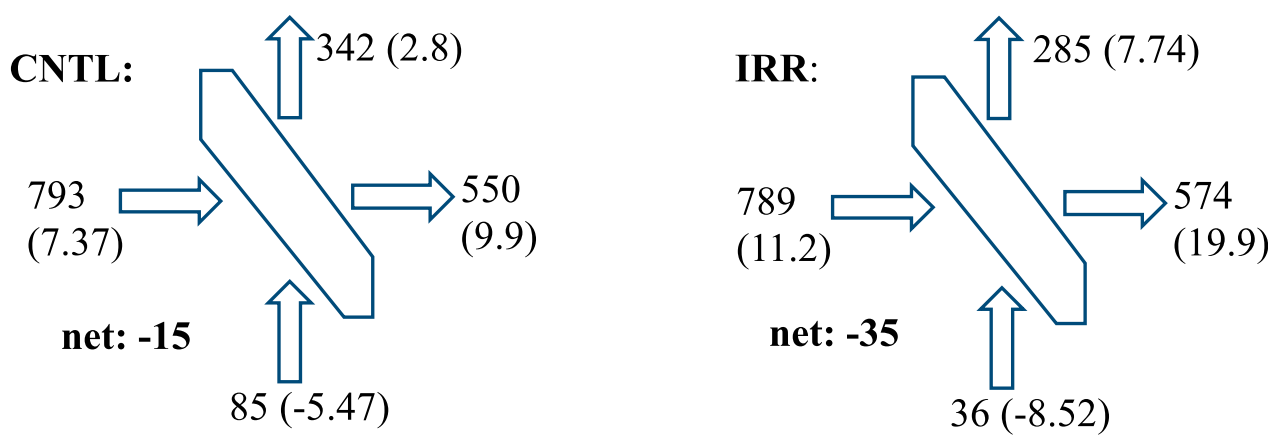

FIG. 8. (top) Terrain height in the model domain (shaded). Red enclosed area represents the CCV for simplicity. (bottom) Averaged JJA vertically integrated moisture flux over the CCV region in the (left) CNTL and (right) IRR simulations $\left(10^{11} \mathrm{~kg}\right.$ month $\left.^{-1}\right)$. Numbers in parentheses indicate the same calculation but for water vapor tracer.

changes induced by the irrigation scheme. Typically, during dry years with relatively dry winter and spring, irrigation will have a larger impact on precipitation, compared to wet years (not shown). This is straightforward since during dry years there will be relatively larger vapor pressure deficit and lower soil moisture that result in increased irrigation compared to wet years. Once the soil moisture deficit is removed, this additional water tends to evaporate into the atmosphere. The entire domain-average precipitation increases by $3.48 \%$ due to irrigation, from 0.86 to $0.89 \mathrm{~mm} \mathrm{day}^{-1}$. Precipitation difference in Fig. 10 suggests a consistent increase in precipitation over the $\mathrm{CRB}$, with average precipitation increases by about $2.9 \%$ from 1.48 to $1.52 \mathrm{~mm} \mathrm{day}^{-1}$. This increase is also found to be robust, varying from $0.64 \%$ to $4.8 \%$ among the 18 ensemble members ( 6 years, each year with three different initial conditions).

Further investigation of the tracer precipitation from the CNTL simulation indicates that water vapor that evaporates from the CCV region tends to move northeastward and precipitate mainly in the state of Oregon and northeastern Idaho, following the climatological wind direction (Fig. 7). After irrigation is implemented, more water vapor evaporates from the CCV and is able to precipitate in Nevada, Idaho, and certain parts of Utah and Colorado. While the increase in tracer precipitation occurs in both wet and dry years over the CRB, the pattern of tracer precipitation increase is confined to northern CRB and thus cannot fully explain the precipitation changes in Fig. 10, where precipitation increase is also seen over Arizona along the Mogollon Rim and part of New Mexico. These results indicate that the precipitation change over the CRB may be not only under the direct impact of additional moisture in the atmosphere due to irrigation, but also due to indirect impacts. Such a finding is also consistent with Lo and Famiglietti (2013), even though they suggested a much higher percentage of $15 \%$ in precipitation increase over the CRB. The ratio of tracer 

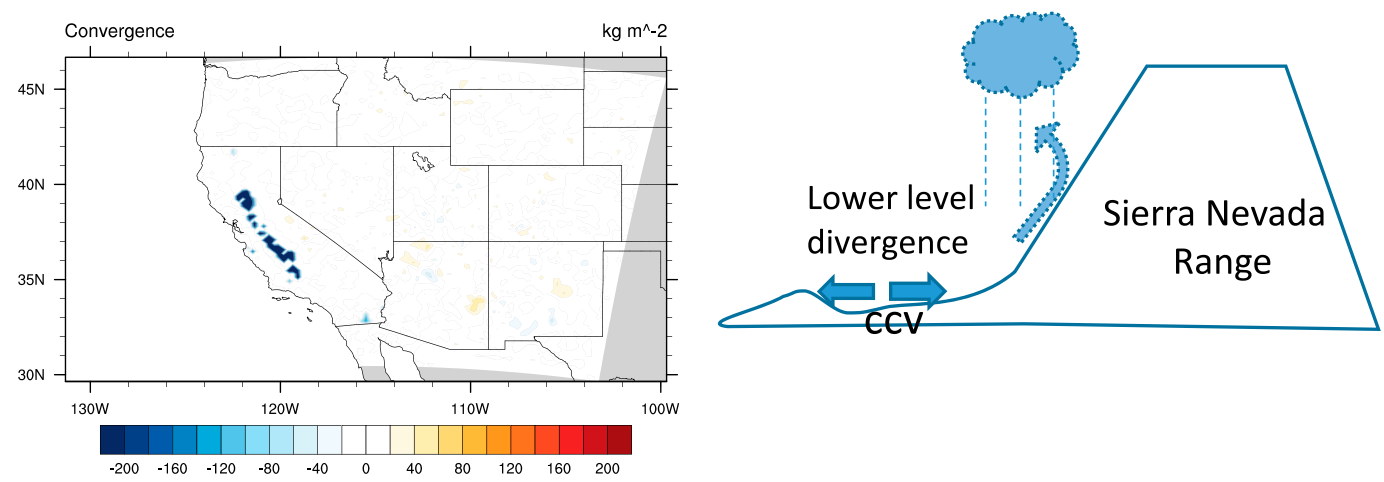

FIG. 9. (left) Difference in convergence between IRR and CNTL simulations for JJA months [see details in Schmitz and Mullen (1996); negative values indicate divergence]. (right) A schematic depiction of how divergence over CCV may affect the upwind side of the Sierra Nevada.

precipitation to total precipitation in Fig. S3 in the supplemental material is consistent with the water vapor mixing ratio difference and the average wind pattern shown in Fig. 7, with magnitude usually less than 5\% except for regions close to $\mathrm{CCV}$.

To explain the possible mechanism by which the IRR scheme produces more precipitation over the domain, we focus mainly on two subdomains as delineated in Fig. 2. California and its nearby region (CNR; red box in Fig. 2) is directly influenced by the additional moisture from irrigation over the CCV (Figs. 7, 10). However, over the CRB the mechanism is likely different, considering precipitation increase over the southern CRB in Arizona and New Mexico where direct moisture contribution from the $\mathrm{CCV}$ has not been detected (Figs. 6, 7, 10).

We look at the precipitation difference over the CNR between the IRR and CNTL simulations by aggregating the 3-hourly precipitation difference into daily precipitation and calculating the running mean of 5-day precipitation difference. As shown in Fig. 11, the distribution of precipitation difference skews toward the positive side, indicating an increase in precipitation in this region, which is in accordance with Fig. 10. Then we define a precipitation difference threshold, corresponding to the 75th percentile of precipitation difference for this region, which equals $+0.71 \mathrm{~mm}^{\text {day }}{ }^{-1}$. Then we plot the composite of $500 \mathrm{hPa}$ geopotential height difference for all pentads that have precipitation difference (IRR - CNTL) greater than $+0.71 \mathrm{~mm}$ day $^{-1}$.

Over the CNR, when precipitation difference is above the 75th percentile, 500-hPa geopotential height difference between IRR and CNTL shows a wave pattern, likely associated with the latent heat release at midlevels (Gall 1976). Gall (1976) had shown that release of latent

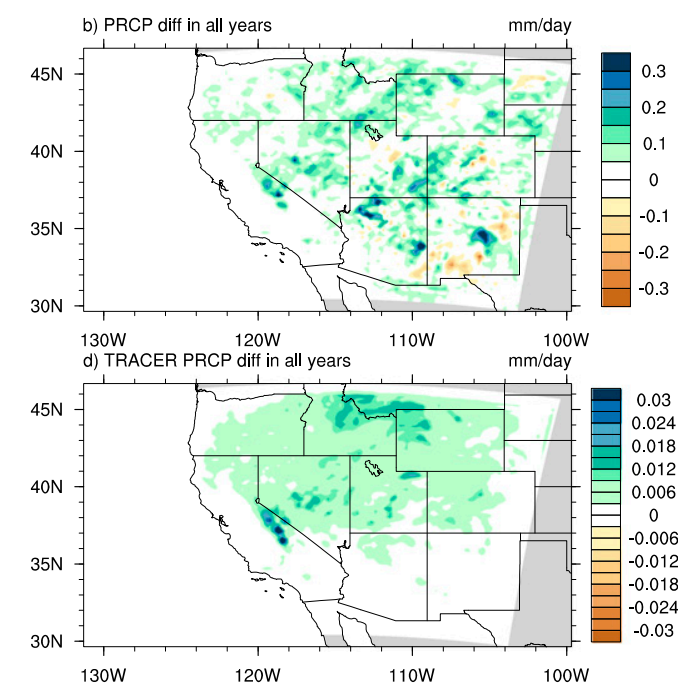

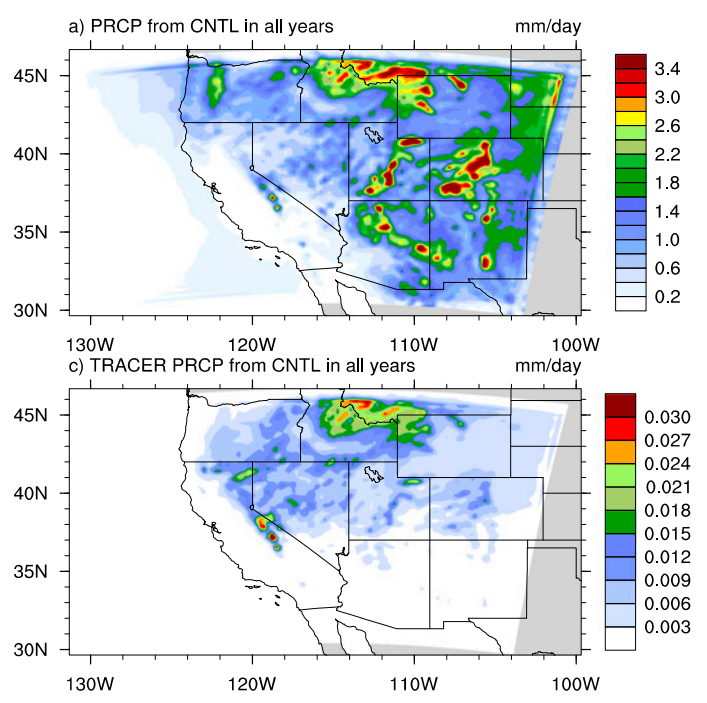

FIG. 10. (a) Simulated average precipitation from all years in CNTL simulation and (b) simulated precipitation difference between IRR and CNTL for all years. (c),(d) As in (a) and (b), but for tracer precipitation $\left(\mathrm{mm} \mathrm{day}^{-1}\right)$. 

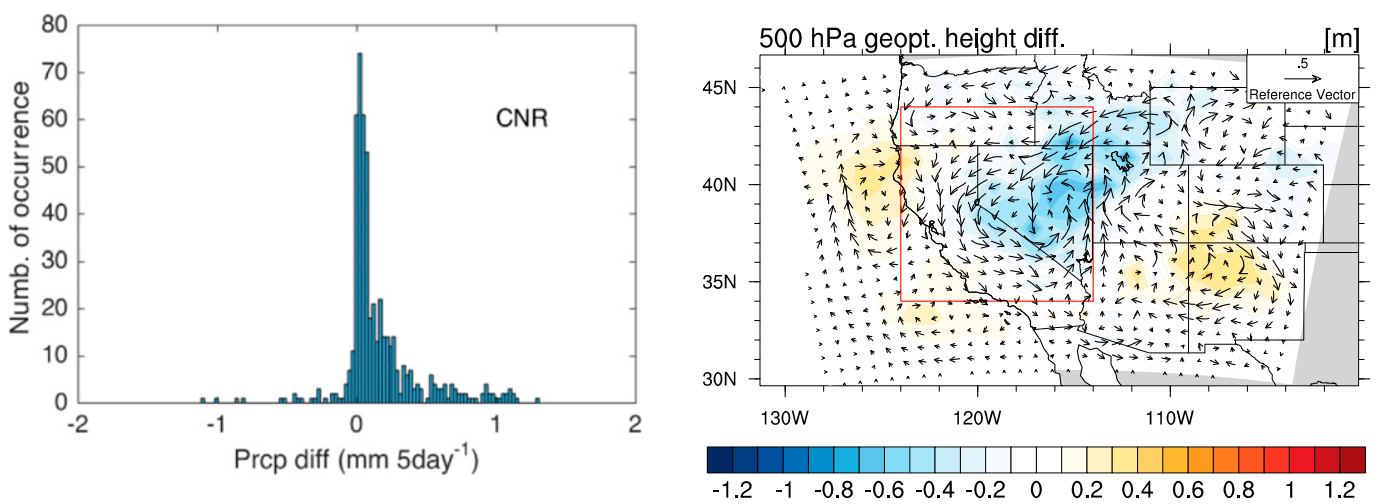

FIG. 11. (left) Distribution of 5-day precipitation difference (IRR - CNTL) over CNR for all years and all ensemble members. The positive skew indicates that precipitation increases over this region. (right) The 500-hPa geopotential height difference between the IRR and CNTL simulations at pentads when precipitation difference over the CNR is above 75 th percentile of its time series. Vectors indicate the wind anomalies at 500-hPa level.

heat would introduce a midlevel $(500 \mathrm{hPa})$ wave of wavenumber 15 (of wavelength $\sim 2000 \mathrm{~km}$ ), which is of comparative size to the wave pattern as displayed in Fig. 11.

As shown in Fig. 10d, CCV irrigation enhances direct precipitation downwind. The geopotential low displayed in Fig. 11 is likely associated with midlevel anomalous latent heat release in this downwind region. The geostrophic winds associated with the geopotential height difference pattern, as seen in Fig. 11, result in strengthened southerly flow along the eastern border of Utah and favor inland penetration of moisture from the Gulf of California. The geopotential high formed over the CRB is similar to the so-called "Four Corners high" during the monsoon season, which can draw moisture from the Gulf of California or the core of the monsoon region and induce thunderstorm events in the southern CRB. Since precipitation difference over CNR is also highly skewed toward the positive side, such a wave pattern has a high probability to form, which is then expected to increase precipitation over the CRB as well. Further analysis shows that during days when the control simulation generates precipitation over the $\mathrm{CRB}$, the irrigation simulation enhances precipitation over the region, and the amplification increases at high-intensity precipitation events. Notably, the changes are not due to the direct effect of moisture from irrigation but due to enhanced southerly moisture transport.

\section{Summary and discussion}

We incorporated an irrigation scheme into the Noah LSM coupled with the regional WRF Model and calibrated the scheme for the agricultural area in the CCV. The convective parameterization scheme (KF scheme) in the WRF Model was also calibrated to reduce the tendency to overestimate precipitation in the domain, thereby reducing bias in both temperature and precipitation. Despite the calibration, a wet bias in simulated precipitation persists.

We conducted experiments with and without the irrigation scheme. Each experiment was run for three wet and three dry years based on soil moisture condition in the previous winter and spring and using three different initial conditions. Air temperature, dewpoint temperature, and relative humidity at $2 \mathrm{~m}$ were evaluated against CIMIS station data. The irrigation scheme resulted in improved simulation of the diurnal cycle of surface variables. Mean absolute bias in diurnal cycle was reduced by $0.7^{\circ} \mathrm{C}, 2.5^{\circ} \mathrm{C}$, and $5.5 \%$ for temperature, dewpoint, and relative humidity, respectively, by including the irrigation scheme. The CNTL simulation tends to have drier and warmer lower atmosphere whereas the irrigation scheme reduced the model bias by adding additional water to the soil, thereby changing the partitioning of energy and leading to stronger evapotranspiration (more latent heat and less sensible heat flux), which lowered air temperature and increased humidity. Comparison of 3-hourly model results from IRR and CNTL simulations with in situ observations suggests that the irrigation scheme is able to reduce model bias by $39 \%, 72 \%, 56 \%$, and $64 \%$ and reduce RMSE by $32 \%$, $50 \%, 38 \%$, and $42 \%$ for surface air temperature, dewpoint temperature, relative humidity, and soil temperature, respectively. Meanwhile, including the irrigation scheme increases correlations with observation as well, thus providing support for the validity of our irrigation scheme.

The daytime vertical profile suggests that local changes between IRR and CNTL mainly exist in the boundary layer. Simulations with irrigation have lower 
potential temperature, higher humidity, and higher instability in the boundary layer. Because of these changes, CAPE increases and LCL height decreases over the $\mathrm{CCV}$. Despite these changes, differences in precipitation are negligible over the CCV because that climatological precipitation in the summer is small over this region. However, analysis of the IRR and CNTL simulations indicates that changes in integrated water vapor occur mainly downwind of the $\mathrm{CCV}$ region. Using water vapor tracers, we find that moisture that evaporates from the $\mathrm{CCV}$ is advected and precipitates northeast of the CCV. Strong divergence over the CCV leads to strengthened zonal moisture outflux, which generates increased precipitation over the windward side of the Sierra Nevada.

While direct evaporation from irrigation contributes to precipitation northwest of the $\mathrm{CCV}$, we also find changes in precipitation in the southwestern United States (CRB). Changes in precipitation over the CRB region are a result of indirect effects, not direct moisture advection. The irrigation simulations reveal a synopticscale geopotential height pattern at $500 \mathrm{hPa}$ likely associated with the release of latent heat. Anomalous low pressure, centered on the state of Utah, enhances cyclonic winds at upper levels and promotes moisture transport from the Gulf of California to the CRB region. In a previous study, Lo and Famiglietti (2013) used the Community Atmosphere Model (CAM) to study the CCV irrigation impact on the CRB. They also found changes in CRB precipitation due to indirect mechanisms and suggested that land-atmosphere interactions over the CRB are the critical mechanism for increased precipitation over the $\mathrm{CRB}$, stating that irrigation over the $\mathrm{CCV}$ acts as a trigger for enhancing precipitation. In our work we present an alternate, although not mutually exclusive, physical mechanism to explain the indirect effect on CRB precipitation.

There are, however, certain aspects that this study is not able to resolve. Even though we have calibrated the $\mathrm{KF}$ scheme, it still tends to overestimate precipitation in the domain, which seems to be associated with structural errors associated with the scheme. Further, a resolution of $20 \mathrm{~km}$ is not fine enough to properly consider topographic effects over the CCV; the CCV is a long narrow valley that lies between the Pacific and the Sierra Nevada and corresponds to only a few grid cells width in the zonal direction. Potentially the model may be smoothing out the topographic effect and thereby omitting certain important effects that the CCV may have on regional climate. Finally, the model resolution may be too coarse to accurately represent the precipitation mechanisms responsible for summer monsoonal precipitation in the southwestern United States (Tripathi and Dominguez 2013).
Acknowledgments. Support for this study has been provided by USDA Award 1295GTA109. We thank Dr. Sandy Dall'erba for his kind support.

\section{REFERENCES}

Adegoke, J. O., R. A. Pielke Sr., J. Eastman, R. Mahmood, and K. G. Hubbard, 2003: Impact of irrigation on midsummer surface fluxes and temperature under dry synoptic conditions: A regional atmospheric model study of the U.S. High Plains. Mon. Wea. Rev., 131, 556-564, doi:10.1175/1520-0493(2003)131<0556: IOIOMS $>2.0 . \mathrm{CO} ; 2$.

Battan, L. J., 1973: Radar Observation of the Atmosphere. University of Chicago Press, $334 \mathrm{pp}$.

Bechtold, P., E. Bazile, F. Guichard, P. Mascart, and E. Richard, 2001: A mass-flux convection scheme for regional and global models. Quart. J. Roy. Meteor. Soc., 127, 869-886, doi:10.1002/ qj.49712757309.

Berg, L. K., and E. I. Kassianov, 2008: Temporal variability of fairweather cumulus statistics at the ACRF SGP site. J. Climate, 21, 3344-3358, doi:10.1175/2007JCLI2266.1.

Bonfils, C., and D. Lobell, 2007: Empirical evidence for a recent slowdown in irrigation-induced cooling. Proc. Natl. Acad. Sci. USA, 104, 13 582-13 587, doi:10.1073/pnas.0700144104.

Chen, F., and J. Dudhia, 2001: Coupling an advanced land surfacehydrology model with the Penn State-NCAR MM5 modeling system. Part II: Preliminary model validation. Mon. Wea. Rev., 129, 587-604, doi:10.1175/1520-0493(2001)129<0587: CAALSH $>2.0 . \mathrm{CO} ; 2$.

DeAngelis, A., F. Dominguez, Y. Fan, A. Robock, M. D. Kustu, and D. Robinson, 2010: Evidence of enhanced precipitation due to irrigation over the Great Plains of the United States. J. Geophys. Res., 115, D15115, doi:10.1029/ 2010JD013892.

de Rosnay, P., J. Polcher, K. Laval, and M. Sabre, 2003: Integrated parameterization of irrigation in the land surface model ORCHIDEE. Validation over Indian Peninsula. Geophys. Res. Lett., 30, 1986, doi:10.1029/2003GL018024.

Dominguez, F., G. Miguez-Macho, and H. Hu, 2016: WRF with water vapor tracers: A study of moisture sources for the North American Monsoon. J. Hydrometeor., 17, 1915-1927, doi:10.1175/ JHM-D-15-0221.1.

Ek, M. B., and L. Mahrt, 1994: Daytime evolution of relative humidity at the boundary layer top. Mon. Wea. Rev., 122, 2709-2721, doi:10.1175/1520-0493(1994)122<2709:DEORHA>2.0.CO;2.

_ , and A. A. M. Holtslag, 2004: Influence of soil moisture on boundary layer cloud development. J. Hydrometeor., 5, 86-99, doi:10.1175/1525-7541(2004)005<0086:IOSMOB >2.0.CO;2.

Eltahir, E. A. B., 1998: A soil moisture-rainfall feedback mechanism: 1. Theory and observations. Water Resour. Res., 34, 765776, doi:10.1029/97WR03499.

Findell, K. L., and E. A. B. Eltahir, 2003: Atmospheric controls on soil moisture-boundary layer interactions. Part I: Framework development. J. Hydrometeor., 4, 552-569, doi:10.1175/ 1525-7541(2003)004<0552:ACOSML $>2.0 . C O ; 2$.

Gall, R., 1976: The effects of released latent heat in growing baroclinic waves. J. Atmos. Sci., 33, 1686-1701, doi:10.1175/ 1520-0469(1976)033<1686:TEORLH>2.0.CO;2.

Haddeland, I., D. P. Lettenmaier, and T. Skaugen, 2006: Effects of irrigation on the water and energy balances of the Colorado and Mekong River basins. J. Hydrol., 324, 210-223, doi:10.1016/j.jhydrol.2005.09.028. 
Han, S., and Z. Yang, 2013: Cooling effect of agricultural irrigation over Xinjiang, northwest China from 1959 to 2006. Environ. Res. Lett., 8, 024039, doi:10.1088/1748-9326/8/2/024039.

Hanson, B., L. J. Schwankl, and A. Fulton, 1999: Scheduling irrigations: When and how much water to apply. Water Management Series 3396, University of California, Davis, 202 pp.

Hong, S.-Y., and H.-L. Pan, 1996: Nonlocal boundary layer vertical diffusion in a medium-range forecast model. Mon. Wea. Rev., 124, 2322-2339, doi:10.1175/1520-0493(1996)124<2322: NBLVDI>2.0.CO;2.

- , and J. Lim, 2006: The WRF single-moment 6-class microphysics scheme (WSM6). J Korean Meteor Soc., 42, 129-151.

Huang, X., and P. A. Ullrich, 2016: Irrigation impacts on California's climate with the variable-resolution CESM. J. Adv. Model. Earth Syst., 8, 1151-1163, doi:10.1002/2016MS000656.

- A. M. Rhoades, P. A. Ullrich, and C. M. Zarzycki, 2016: An evaluation of the variable-resolution CESM for modeling California's climate. J. Adv. Model. Earth Syst., 8, 345-369, doi:10.1002/2015MS000559.

Juang, J. Y., A. Porporato, P. C. Stoy, M. S. Siqueira, A. C. Oishi, M. Detto, H. S. Kim, and G. G. Katul, 2007: Hydrologic and atmospheric controls on initiation of convective precipitation events Water Resour. Res, 43, W03421, doi:10.1029/2006WR004954.

Kain, J. S., 2004: The Kain-Fritsch convective parameterization: An update. J. Appl. Meteor., 43, 170-181, doi:10.1175/ 1520-0450(2004)043<0170:TKCPAU>2.0.CO;2.

- and J. M. Fritsch, 1990: A one-dimensional entraining detraining plume model and its application in convective parameterization. J. Atmos. Sci., 47, 2784-2802, doi:10.1175/ 1520-0469(1990)047<2784:AODEPM > 2.0.CO;2.

__ and __ 1993: Convective parameterization for mesoscale models: The Kain-Fritsch scheme. The Representation of Cumulus Convection in Numerical Models, Meteor. Monogr., No. 46, Amer. Meteor. Soc., 165-170, doi:10.1007/ 978-1-935704-13-3_16.

Kanamaru, H., and M. Kanamitsu, 2008: Model diagnosis of nighttime minimum temperature warming during summer due to irrigation in the California Central Valley. J. Hydrometeor., 9, 1061-1072, doi:10.1175/2008JHM967.1.

Li, J., X. Gao, and S. Sorooshian, 2007: Modeling and analysis of the variability of the water cycle in the upper Rio Grande basin at high resolution. J. Hydrometeor., 8, 805-824, doi:10.1175/JHM602.1.

Liang, X.-Z., L. Li, K. E. Kunkel, M. Ting, and J. X. L. Wang, 2004: Regional climate model simulation of U.S. precipitation during 1982-2002. Part I: Annual cycle. J. Climate, 17, 3510-3529, doi:10.1175/1520-0442(2004)017<3510:RCMSOU>2.0.CO;2.

Lo, M.-H., and J. S. Famiglietti, 2013: Irrigation in California's Central Valley strengthens the southwestern U.S. water cycle. Geophys. Res. Lett., 40, 301-306, doi:10.1002/grl.50108.

Loikith, P. C., D. E. Waliser, H. Lee, J. D. Neelin, B. R. Lintner, S. McGinnis, L. O. Mearns, and J. Kim, 2015: Evaluation of large-scale meteorological patterns associated with temperature extremes in the NARCCAP regional climate model simulations. Climate Dyn., 45, 3257-3274, doi:10.1007/s00382-015-2537-x.

Marcella, M. P., and E. A. B. Eltahir, 2014: Introducing an irrigation scheme to a regional climate model: A case study over West Africa. J. Climate, 27, 5708-5723, doi:10.1175/JCLI-D-13-00116.1.

Mesinger, F., and Coauthors, 2006: North American Regional Reanalysis. Bull. Amer. Meteor. Soc., 87,343-360, doi:10.1175/ BAMS-87-3-343.

Miguez-Macho, G., A. Rios-Entenza, and F. Dominguez, 2013: The impact of soil moisture and evapotranspiration fluxes on the spring water cycle in the Iberian Peninsula: A study with moisture tracers in WRF. 2013 Fall Meeting, San Francisco, CA, Amer. Geophys. Union, Abstract H12B-05.

Mlawer, E. J., S. J. Taubman, P. D. Brown, M. J. Iacono, and S. A. Clough, 1997: Radiative transfer for inhomogeneous atmospheres: RRTM, a validated correlated- $k$ model for the longwave. J. Geophys. Res., 102, 16663-16682, doi:10.1029/97JD00237.

Ozdogan, M., M. Rodell, H. K. Beaudoing, and D. L. Toll, 2010: Simulating the effects of irrigation over the United States in a land surface model based on satellite-derived agricultural data. J. Hydrometeor., 11, 171-184, doi:10.1175/2009JHM1116.1.

Qian, Y., M. Huang, B. Yang, and L. K. Berg, 2013: A modeling study of irrigation effects on surface fluxes and land-air-cloud interactions in the southern Great Plains. J. Hydrometeor., 14, 700-721, doi:10.1175/JHM-D-12-0134.1.

Sacks, W. J., B. I. Cook, N. Buenning, S. Levis, and J. H. Helkowski, 2008: Effects of global irrigation on the near-surface climate. Climate Dyn., 33, 159-175, doi:10.1007/s00382-008-0445-z.

Schmitz, J. T., and S. L. Mullen, 1996: Water vapor transport associated with the summertime North American monsoon as depicted by ECMWF analyses. J. Climate, 9, 1621-1634, doi:10.1175/1520-0442(1996)009<1621:WVTAWT>2.0.CO;2.

Siebert, S., P. Doll, J. Hoogeveen, J. M. Faures, K. Frenken, and S. Feick, 2005: Development and validation of the global map of irrigation areas. Hydrol. Earth Syst. Sci., 9, 535-547, doi:10.5194/hess-9-535-2005.

, V. Henrich, K. Frenken, and J. Burke, 2013: Update of the Digital Global Map of Irrigation Areas to version 5. Project Rep., University of Bonn/FAO, 171 pp. [Available online at https://www.lap.uni-bonn.de/research/downloads/gmia/siebert_ et_al_2013_gmia5.]

Skamarock, W., and Coauthors, 2008: A description of the Advanced Research WRF version 3. NCAR Tech. Note NCAR/ TN-475+STR, 113 pp., doi:10.5065/D68S4MVH.

Sorooshian, S., J. Li, K. L. Hsu, and X. Gao, 2011: How significant is the impact of irrigation on the local hydroclimate in California's Central Valley? Comparison of model results with ground and remote-sensing data. J. Geophys. Res., 116, D06102, doi:10.1029/2010JD014775.

Tripathi, O. P., and F. Dominguez, 2013: Effects of spatial resolution in the simulation of daily and subdaily precipitation in the southwestern US. J. Geophys. Res. Atmos., 118, 75917605, doi:10.1002/jgrd.50590.

Yan, H., Y. Qian, G. Lin, L. R. Leung, B. Yang, and Q. Fu, 2014: Parametric sensitivity and calibration for the Kain-Fritsch convective parameterization scheme in the WRF Model. Climate Res., 59, 135-147, doi:10.3354/cr01213.

Yang, B., Y. Qian, G. Lin, R. Leung, and Y. Zhang, 2012: Some issues in uncertainty quantification and parameter tuning: A case study of convective parameterization scheme in the WRF regional climate model. Atmos. Chem. Phys., 12, 2409-2427, doi:10.5194/acp-12-2409-2012.

, Y. Zhang, Y. Qian, J. Tang, and D. Liu, 2016: Climatic effects of irrigation over the Huang-Huai-Hai Plain in China simulated by the Weather Research and Forecasting Model. J. Geophys. Res. Atmos., 121, 2246-2264, doi:10.1002/2015JD023736.

Yang, Z., F. Dominguez, H. Gupta, X. Zeng, and L. Norman, 2016: Urban effects on regional climate: A case study in the Phoenix and Tucson "Sun Corridor." Earth Interact., 20, doi:10.1175/EI-D-15-0027.1.

Yin, J., J. D. Albertson, J. R. Rigby, and A. Porporato, 2015: Land and atmospheric controls on initiation and intensity of moist convection: CAPE dynamics and LCL crossings. Water Resour. Res., 51, 8476-8493, doi:10.1002/2015WR017286. 